\title{
Over-the-scope clip closure of oesophageal perforation after pneumatic dilatation for achalasia
}

\begin{abstract}
Pneumatic dilatation of the oesophagus is the first line method of therapy of achalasia. Pneumatic balloon dilatation induces forceful stretching of the lower oesophageal sphincter (LES), which weakens the LES by tearing its muscle fibers. Complications of Pneumatic balloon dilatation include oesophageal perforation in $1.6 \%$ and heartburn in $45 \%$. Recently endoscopic approach has been introduced in treating gastrointestinal perforations which is less invasive than surgery and have the advantages of lesser morbidity and mortality, shorter hospital stay, and shorter periods of avoiding oral feeding. The main endoscopic methods used to close GI perforations are endoclips and covered self-expandable stents the margins. We report the case of a 51year-old female patient presenting with oesophageal tear after pneumatic dilatation for achalasia. Over-the-scope clip (OTSC) was used for the Closure of the oesophageal tear. To the best of our knowledge this is the first case report of successful closure of oesophageal tear secondary to post pneumatic dilation of the oesophagus for the treatment of Achalasia using the OTSC.
\end{abstract}

Keywords: oesophageal achalasia, pneumatic dilatation for achalasia, over-the-scope clip, oesophageal perforation, achalasia of the cardiac
Volume 3 Issue I - 2015

\author{
Mazen Naga, Serag Esmat \\ Department of Internal Medicine-Gastroenterology Division, \\ Cairo University, Egypt
}

Correspondence: Serag Esmat, Assistant professor of Interna Medicine and Gastroenterology, Faculty of Medicine, Cairo University, 18 Elamin, St. Mohandissin, Giza, Postal Code: I24I I, Egypt, Tel 2.01222190974, Fax 00202-33026I58, Emsilseragesmat@kasralainy.edu.eg

Received: October 30, 2015 | Published: December 02, 2015
Abbreviations: OTSC, over-the-scope clip; LES, lower esophageal sphincter; PD, pneumatic dilatation; TTS, Through The Scope Clips

\section{Introduction}

Achalasia is an esophageal disease due to inability of relaxation of the lower esophageal sphincter (LES), frequently associated with loss of peristalsis in the distal esophagus results from the degeneration of ganglion cells in the myenteric plexus in the esophageal wall., Pneumatic dilatation (PD) of the esophagus is the first line method of therapy of achalasia. Pneumatic balloon dilatation induce forceful stretching of the lower esophageal sphincter, which weakens the LES by tearing its muscle fibers. ${ }^{3,4}$

Complications of Pneumatic balloon dilatation includes esophageal perforation in $1.6 \%$ and heartburn in $45 \% .^{5}$ Gastrointestinal perforations have been managed mainly by surgery. Recently endoscopic approach has been introduced which is less invasive than surgery and have the advantages of lesser morbidity and mortality, shorter hospital stay, and shorter periods of avoiding oral feeding. ${ }^{6,7}$ The main endoscopic methods used to close GI perforations are endoclips and covered self-expandable stents. ${ }^{8,9}$ To the best of our knowledge we report the first case of using Over-the-scope clip in the closure of esophageal perforation secondary to pneumatic dilatation for achalasia.

\section{Case report}

This is a 51year-old female, who presented with history of gradual progressive dysphagia to liquids and solid foods and sometimes food regurgitation in the last 2years. Physical examination revealed unremarkable findings. A barium swallow was ordered and revealed dilated distal esophageal lumen and narrowing of the gastroesophageal junction. Upper endoscopic examination showed a dilated esophagus with food retention at a smooth narrowing of the gastroesophageal junction denoting the presence of Achalasia. Esophageal manometry was performed and showed: aperistalsis, incomplete lower oesophageal sphincter (LES) relaxation and increased basal LES pressure.

A Rigiflex balloon dilator (Boston Scientific, Boston, MA, USA) with a diameter of $30 \mathrm{~mm}$ was used under endoscopic control for pneumatic esophageal dilatation. She was fine after PD a part from mild chest pain. In the next day the patient started to complain from increasing severity of her chest pain. A Multislice post contrast CT scan of the chest and abdomen with oral contrast showed a Leaking oral contrast is seen along the left side of the termination of the dorsal esophagus (Figure 1).

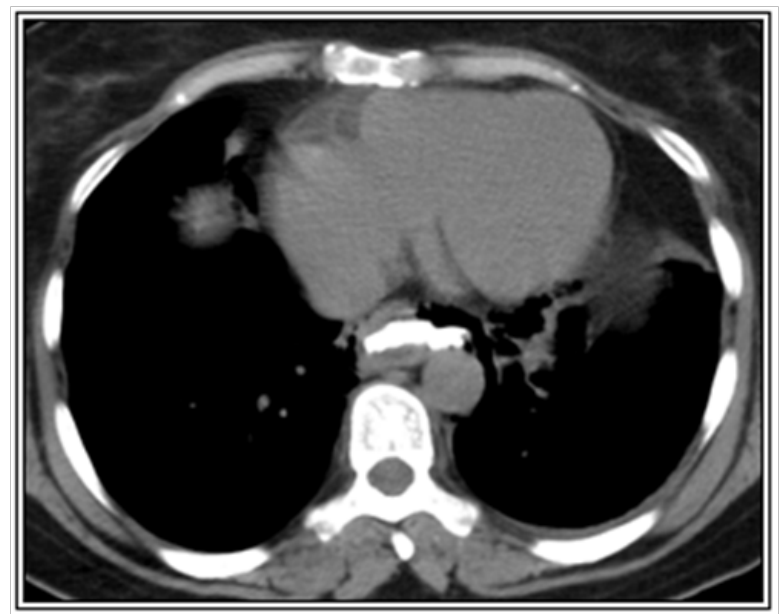

Figure I Contrast enhanced CT scan of the chest and abdomen with oral contrast showed a Leaking oral contrast is seen along the left side of the termination of the dorsal esophagus.

Another upper endoscopy was done and a distal tear was visualized at the distal end (Figure 2), Over-the-scope clip (OTSC) was used to close this tear (Figure 3) (Video). After the closure of the oesophageal, tear with OTSC, CT gastrografin was performed which showed minimal oesophageal leakage (Figure 4). 


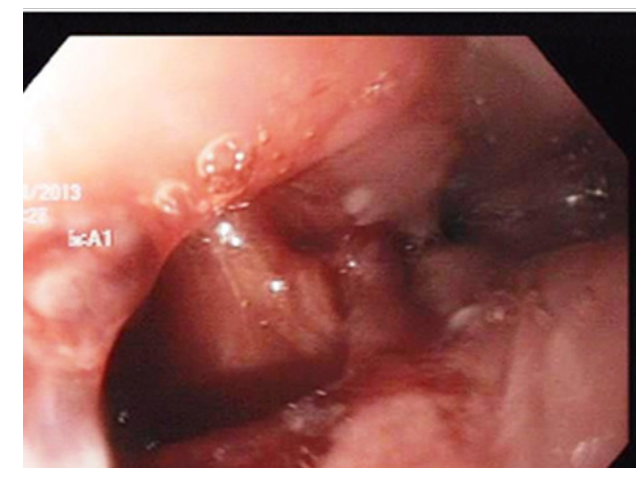

Figure 2 Upper endoscopic picture showing the oesophageal tear visualized at the distal end.

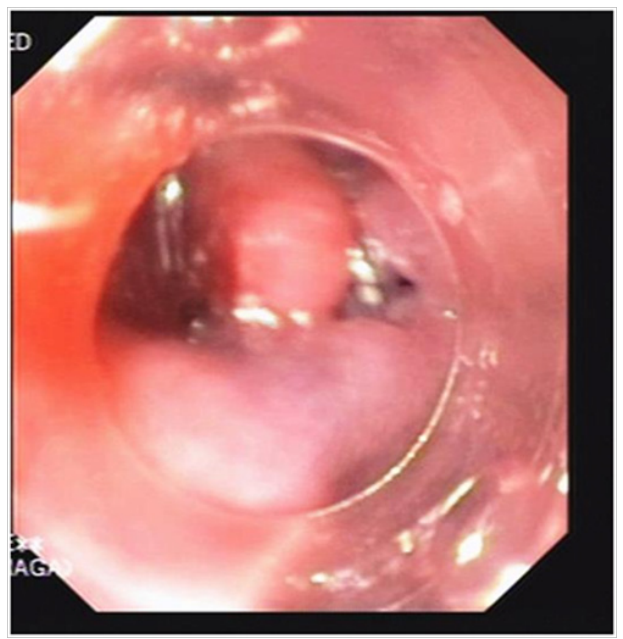

Figure 3 Upper endoscopic picture showing the use Over-the-scope clip (OTSC) to close oesophageal tear.

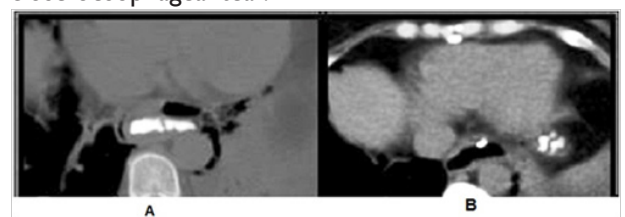

Figure 4 Contrast enhanced CT showing the oesophageal leakage before (A) and after closure of the tear (B) the leakage became minimal.

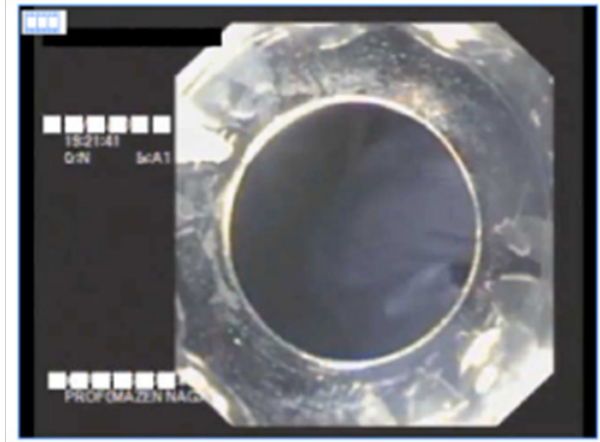

Video File: Video showing the closing of the oesophageal with the OTSC.

\section{Discussion}

The OTSC is different from through the scope clips (TTS $)^{10}$ the OTSC is loaded on a cap placed on the scope tip, and has the ability to clench and compress the tissue more widely and with greater strength, without causing ischemia or cutting the tissue, and ${ }^{6} \mathrm{~A}$ small case series showed that the OTSC is effective for hemostasis of nonvariceal bleeding. OTSC was used successfully in closure of gastric and colonic perforations. ${ }^{11-13}$

To the best of our knowledge this is the first case report of successful closure of oesophageal tear secondary to post pneumatic dilation of the oesophagus for the treatment of Achalasia using the OTSC. The patient was discharged after 14days to receive home care. The chest pain gradually subsided and disappeared before discharge. Follow up at outpatient clinic at one, three, six and twelve month later revealed continuous improvement of dysphagia and regurgitation. Currently the patient is asymptomatic.

\section{Acknowledgments}

None.

\section{Conflicts of interest}

Author declares there are no conflicts of interest.

\section{Funding}

None.

\section{References}

1. Park W, Vaezi MF. Etiology and pathogenesis of achalasia: the current understanding. Am J Gastroenterol. 2005;100(6):1404-1414.

2. Paterson WG. Etiology and pathogenesis of achalasia. Gastrointest Endosc Clin N Am. 2001;11(2):249-266.

3. Chuah $\mathrm{SK}, \mathrm{Wu} \mathrm{KL}, \mathrm{Hu} \mathrm{TH}$, et al.Endoscope-guided pneumatic dilation for treatment of esophageal achalasia. World J Gastroenterol. 2010;16(4):411-417.

4. Lake JM, Wong RK. Review article: the management of achalasia - a comparison of different treatment modalities. Aliment Pharmacol Ther. 2006;24(6):909-918.

5. Campos GM, Vittinghoff E, Rabl C, et al. Endoscopic and surgical treatments for achalasia: a systematic review and meta-analysis. Ann Surg. 2009;249(1):45-47.

6. Kiev J, Amendola M, Bouhaidar D, et al. A management algorithm for esophageal perforation. Am J Surg. 2007;194 (1):103-106.

7. Freeman RK, Ascioti AJ, Wozniak TC. Postoperative esophageal leak management with the Polyflex esophageal stent. J Thorac Cardiovasc Surg. 2007;133(2):333-338.

8. Tierney W, Chuttani R, Croffie J, et al. Enteral stents. Gastrointest Endosc. 2006;63(7):920-926.

9. Chuttani R, Barkun A, Carpenter S, et al. Endoscopic clip application devices. Gastrointest Endosc. 2006;63(6):746-750.

10. Chung MA, Wanebo HJ. Surgical management and treatment of gastric and duodenal fistulas. Surg Clin North Am. 1996;76(5):1137-1146.

11. Kirschniak A, Kratt T, Stüker D, et al. A new endoscopic over-the-scope clip system for treatment of lesions and bleeding in the GI tract: first clinical experiences. Gastrointest Endosc. 2007;66(1):162-167.

12. Repici A, Arezzo A, De Caro G, et al. Clinical experience with a new endoscopic over-the-scope clip system for use in the GI tract. Dig Liver Dis. 2009;41(6):406-410.

13. Kirschniak A, Traub F, Kueper MA, et al. Endoscopic treatment of gastric perforation caused by acute necrotizing pancreatitis using overthe scope clips: a case report. Endoscopy. 2007;39(12):1100-1102. 